\title{
Hardening or softening? An observational study of changes to the prevalence of hardening indicators in Victoria, Australia, 2001-2016
}

\author{
Emily Brennan (1) , Elizabeth M Greenhalgh (1) , Sarah J Durkin (ㄷ) , \\ Michelle M Scollo @ , Linda Hayes 도, Melanie A Wakefield
}

\section{- Additional material is published online only. To view please visit the journal online (http://dx.doi.org/10.1136/ tobaccocontrol-2019-054937) \\ Cancer Council Victoria, Melbourne, Victoria, Australia \\ Correspondence to Dr Emily Brennan, Cancer Council Victoria, Melbourne, VIC 3004, Australia; \\ emily.brennan@cancervic. org.au}

Received 10 January 2019 Revised 3 April 2019 Accepted 5 April 2019 Published Online First 30 May 2019

\section{SLinked}

- http://dx.doi.org/10.1136/ tobaccocontrol-2019-055067

Check for updates

(c) Author(s) (or their employer(s)) 2020. No commercial re-use. See rights and permissions. Published by BMJ.

To cite: Brennan $\mathrm{E}$, Greenhalgh EM, Durkin SJ, et al. Tob Control 2020:29:252-257.

\section{ABSTRACT}

Background The hardening hypothesis predicts that as smoking prevalence declines, remaining smokers will be more heavily addicted to nicotine and/or less interested in quitting. We tested this hypothesis in a population exposed to a comprehensive tobacco control programme over a 16-year period.

Methods Annual cross-sectional surveys randomly sampled adults (aged 26+) in the state of Victoria, Australia, between 2001 and 2016. Until 2010, participants were recruited through random digit dialling to landline telephones; from 2011, sampling frames also included mobile phones. Logistic regressions assessed changes over time in the prevalence of smoking and each hardening indicator; additional models examined interactions by sex, age, education and socioeconomic status.

Results Smoking prevalence declined significantly between 2001 and 2016 (20.1\%-13.0\%), as did the prevalence of seven hardening indicators: daily smoking, heavy consumption, no quit attempt in the past 5 years or past 12 months, no intention to quit in the next 6 months or next 30 days, and happiness to keep smoking. In addition, the proportion of smokers defined as 'hardcore' decreased from $17.2 \%$ to $9.1 \%$. On the whole, hardening indicators decreased to a similar extent among demographic subgroups.

Conclusions These results are inconsistent with the hardening hypothesis. Rather, they suggest that a comprehensive tobacco control programme that combines provision of cessation support to individual smokers with implementation of population-level interventions to drive all smokers towards quitting, can successfully reduce both smoking prevalence and levels of dependence and desire to keep smoking among the remaining population of smokers.

\section{INTRODUCTION}

As smoking rates decline in many countries due to comprehensive tobacco control programmes, some have argued that a greater proportion of the remaining smokers are likely to be 'hardcore', usually conceptualised as those who are unwilling or unable to quit and likely to remain so. ${ }^{2}$ Also known as the 'hardening hypothesis', 2 this account predicts that, compared with earlier generations, present-day smokers will be more heavily addicted and/or will increasingly comprise smokers who have little motivation or interest in quitting. ${ }^{3}$

If the hardening hypothesis is true, existing tobacco control strategies that address prevention and cessation at the population level may fail to impact hardcore smokers. ${ }^{4}$ Hardening would also have implications for 'endgame' strategies, which may be unfeasible if the remaining smokers are incapable of quitting, either due to substantial nicotine dependence or an unwillingness to try. ${ }^{4}$ This question has become more pertinent with the emergence of e-cigarettes and heated tobacco products. If a growing proportion of smokers cannot quit using established cessation aids, some have argued that tobacco harm reduction should be considered a viable strategy. ${ }^{5}$

Most tests of the hardening hypothesis have examined changes over time in the prevalence of hardcore behaviours ('hardening indicators'), ${ }^{6-9}$ or correlations between smoking prevalence and the prevalence of hardening indicators. ${ }^{4} 10$ Common hardening indicators include measures of nicotine dependence and quitting intent and activity. ${ }^{411} 12$ Smokers that report both high dependence and low quitting activity are generally identified as hardcore smokers, and an increase in the proportion of such smokers over time-alongside declining smoking prevalence-would also indicate hardening. ${ }^{4}$

Encouragingly, most evidence to date does not support the hardening hypothesis. Hardcore smokers comprise a minority of smokers, ${ }^{11}$ and research in the USA, ${ }^{69}$ New Zealand ${ }^{3}$ and Europe $^{7813}$ consistently finds either no change in hardening indicators or even a 'softening' of the smoking population. Australian studies have similarly found no evidence of hardening among smokers overall. ${ }^{1415}$

Nonetheless, a small number of studies have suggested hardening may be occurring. ${ }^{16-19}$ One found that the proportion of smokers in England with low motivation to quit and high dependence increased over time. ${ }^{18}$ Another found that nicotine dependence scores were higher in countries with lower smoking rates. ${ }^{19}$ However, critics of these studies have argued they do not provide strong evidence of hardening, citing a range of conceptual and methodological limitations. ${ }^{40-22}$

Others suggest that, while the overall proportion of hardcore smokers may not be increasing, subgroups who have more difficulty quitting are becoming a larger fraction of the remaining smoking population. ${ }^{2}$ Australian data from 2001 to 2010 showed that while the proportion of hardcore smokers within high socioeconomic status (SES) groups decreased, no such decrease was found in low SES groups. ${ }^{15}$ US researchers also found some 


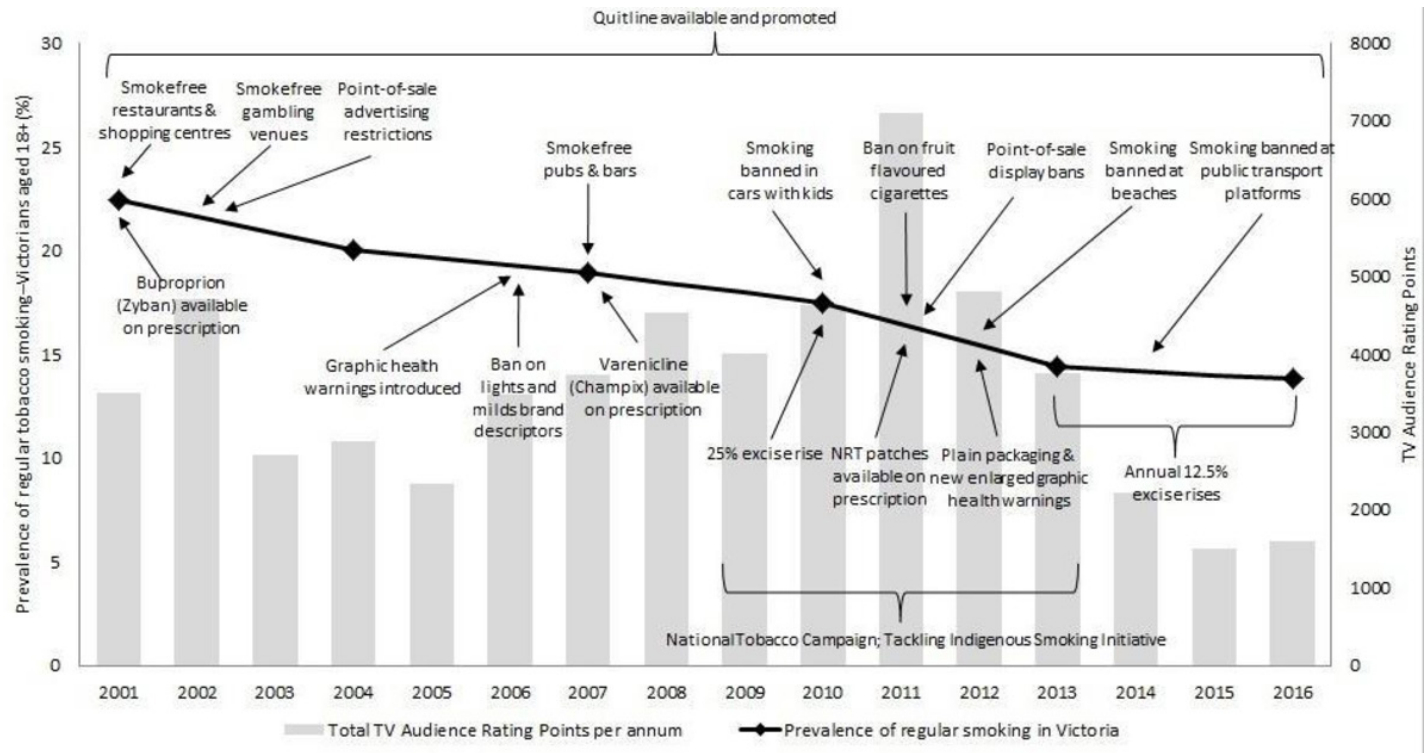

Figure 1 Smoking prevalence, and examples of state (above the line) and national (below the line) tobacco control interventions in the state of Victoria, Australia 2001-2016. Smoking prevalence data obtained from the Australian National Drug Strategy Household Survey (NDSHS) which is conducted every 3 years; all data weighted to the population appropriate for each survey year. Regular smoking includes those reporting that they smoke daily or at least weekly, and includes those smoking any combination of cigarettes, pipes or cigars. Data obtained from Centre for Behavioural Research in Cancer analysis of NDSHS data, as reported in Tobacco in Australia: Facts and Issues, figure 1.13.2. ${ }^{46}$ Television Target Audience Rating Points (TARPs), a measure of reachxfrequency of advertising, whereby 4800 TARPs/year is equal to $100 \%$ of the television audience being exposed to 48 ads per year or $50 \%$ being exposed to 24 ads per year), obtained from Nielsen/Oztam and prepared by the Centre for Behavioural Research in Cancer. NRT, nicotine replacement therapy.

evidence of hardening among specific subgroups, including women and low-income smokers. ${ }^{6}$

Even if declines in hardcore smokers have occurred only among more advantaged groups, this nonetheless demonstrates that such smokers are able to quit given the right conditions and support. ${ }^{2} 15$ Understanding the groups for which hardening may be occurring-or whether it is indeed occurring for the general population-provides a useful starting point to adapt interventions.

The present study examines changes in the prevalence of several hardening indicators and hardcore smokers, among smokers in the state of Victoria, Australia between 2001 and 2016. The study makes three critical advances on past research; by examining a long time period, employing a range of hardening indicators and examining trends among demographic subgroups, it provides more robust evidence as to whetherand among whom-hardening may be occurring. As shown in figure 1 , over this 16-year period, Victorians were exposed to a comprehensive tobacco control programme that included varying levels of mass media campaign activity, cessation support, smokefree legislation, graphic health warnings, tobacco excise increases and restrictions on tobacco marketing including plain packaging. ${ }^{23-25}$ Against this backdrop, the prevalence of regular smoking among Victorian adults declined from 22.4\% in 2001 to $13.8 \%$ in $2016 .{ }^{26}$ If the remaining smokers in Victoria have hardened, then hardening indicators will have become more prevalent since 2001. We tested hardening across time among all current smokers and by sex, age, education level and SES.

\section{METHODS}

\section{Sample and procedure}

Data are from annual cross-sectional telephone surveys in Victoria, Australia. In November and December each year between 2001 and 2016, a research company interviewed randomly sampled adults. Interviews were conducted in English, and verbal consent was obtained from participants. The sample size varied from

a minimum $\mathrm{N}=1963$ in 2001 to a maximum $\mathrm{N}=4503$ in 2008. Prior to 2011, the sample frame was generated exclusively through random digit dialling (RDD) to landline telephones. From 2011, a dual sampling frame was used, with a proportion of respondents recruited via RDD to mobile phones. Reflecting changing phone usage patterns over time, the proportion recruited via mobiles increased from 22\% in 2011 to $60 \%$ in 2016. Additional methodological details are reported elsewhere. $^{23252728}$

Consistent with several other studies of hardcore smoking, ${ }^{13} 182930$ our sample was restricted to current smokers aged $26+$. This excluded younger smokers who may have still been engaged in smoking uptake. ${ }^{18}$

\section{Measures}

\section{Smoking status}

Those who smoked any tobacco (manufactured cigarettes, rollyour-own cigarettes, cigars, pipes or other tobacco products) daily, weekly or less than weekly were classified as current smokers.

\section{Hardening indicators}

Two hardening indicators related to nicotine dependence: the proportion of current smokers who were daily smokers, and the proportion who smoked $16+$ cigarettes per day on average which we defined as heavy consumption. ${ }^{31}$ Five hardening indicators related to interest in quitting. Using responses to 'Approximately how many times, if any, have you tried to give up smoking?' and 'How long ago did your last attempt to quit smoking end?', we calculated the proportion of current smokers who had never 
attempted to quit, had made no quit attempt in the past 5 years, and had made no quit attempt in the past 12 months. Using responses to 'Are you seriously considering quitting smoking in the next 6 months', we calculated the proportion with no intention to quit in the next 6 months. Respondents who indicated that they were considering quitting in the next 6 months were further asked whether they planned to quit within the next 30 days, and we calculated the proportion with no intention to quit in the next 30 days.

As an additional hardening indicator, in the 2001 to 2006, 2010, 2011 and 2013 to 2016 surveys, smokers were asked 'Do you think you should quit sometime in the future, or are you happy to smoke for the rest of your life?' We report the proportion who were happy to smoke for the rest of their life.

\section{Hardcore smokers}

Similar to previous studies, ${ }^{29} 303233$ we defined hardcore smokers as those who: smoked every day; smoked $16+$ cigarettes per day; had not made a quit attempt within the past 12 months; and did not intend to quit within the next 6 months.

We also identified a group who appeared to have given up trying to quit after several unsuccessful quit attempts. The given up giving up group was defined as those who: smoked every day; had previously made 5 or more quit attempts; had not made a quit attempt within the past 5 years; and did not intend to quit within the next 6 months.

\section{Demographic variables}

Respondents provided their sex (male; female), age (26-29; $30-49 ; 50+$ ), and highest level of education attained (low education, did not finish high school or higher qualifications; high education, finished high school or further studies). SES was measured using the Australian Bureau of Statistics' Index of Socio-Economic Disadvantage, using Census data of the postcode area in which respondents resided. ${ }^{34}$ This index ranks postcodes on a continuum of disadvantage, considering characteristics such as income, education, occupation and housing. Respondents from 2001 to 2003 were classified using 2001 Census data; 2006 Census data were used to classify respondents from 2004 to 2008; and 2011 Census data were used to classify respondents from 2009 to 2016 . Postcodes were initially classified into five quintiles, but were collapsed into two categories for analysis: low SES (first and second quintiles; high disadvantage) vs mid-high SES (third, fourth and fifth quintiles; low disadvantage).

\section{Statistical analysis}

All data were weighted using a multi-stage weighting procedure. First, a design weight accounted for the relative chance of inclusion in the landline and/or mobile phone sampling frames and adjusted for the chance of selection based on the number of landlines in each household and the number of in-scope persons per household. Next, data were weighted by age and sex using estimates from the 2006 Census $^{35}$ for data collected between 2001 and 2010, and estimates from the 2011 Census $^{36}$ for data collected between 2011 and 2016.

Analyses were conducted in Stata V.14.2, and accommodated data weighting. First, we assessed changes over time in each hardening indicator and the prevalence of hardcore smokers using a logistic regression in which year was entered as a continuous predictor. Second, we estimated adjusted percentages of each outcome in each year using an additional logistic regression in which year was entered as a categorical predictor. All regression models adjusted for sex, age (26-29; 30-49; 50+), education and SES. An additional set of models for each outcome tested four interaction terms: year $\times$ sex, year $\times$ age, year $\times$ education and year $\times$ SES (one interaction term per model; year entered as a continuous predictor), and we used stratified models to assess subgroup differences in changes over time in each hardening indicator. In interaction tests and stratified models, age was entered as a binary variable $(26-49 ; 50+)$, due to very small numbers of people aged 26-29 years in some years (minimum $n=43$ in 2002). Due to the large number of statistical tests conducted, an alpha of 0.01 was used as the criterion level of statistical significance.

Sensitivity analyses explored the impact of varying definitions of hardcore smokers. First, reflecting the definitions of hardcore smoking used in some previous studies, ${ }^{29} 37$ the criterion that smokers had not made a quit attempt within the past 12 months was replaced with the more stringent criterion of having never attempted to quit (hardcore smokers: smoked every day, smoked $16+$ cigarettes per day, had never attempted to quit and did not intend to quit within the next 6 months). Then, in two additional models, the heavy consumption criterion was removed from the definition, given that consumption may reflect the impact of tobacco control policies (eg, smokefree policies and tax increases) reducing opportunities to smoke, rather than individual-level dependence on nicotine. ${ }^{38}$

\section{RESULTS}

Among Victorian adults aged 26+, the prevalence of current smokers declined significantly from $20.1 \%$ in 2001 to $13.0 \%$ in 2016 (adjusted (A)OR $=0.98,95 \%$ CI 0.98 to 0.99 ). From a total of $\mathrm{N}=7958$ current smokers aged $26+$, we excluded $n=34(0.4 \%)$ who had incomplete data across the four demographic covariates (leaving $\mathrm{n}=7924$ ). Due to missing data on the outcome (including because of 'don't know/can't say' responses), the available $\mathrm{N}$ was slightly lower for most models; where data was missing, it applied to a maximum of $4.9 \%$ of cases (per outcome variable) (see online appendix $\mathrm{A}$ in the supplementary material).

As shown in figure 2 (and online appendix $A$ in the supplementary material), the proportion of current smokers aged $26+$ who were daily smokers decreased from $84.2 \%$ in 2001 to $79.7 \%$ in 2016, which was a significant linear decline $(\mathrm{AOR}=0.96,95 \% \mathrm{CI} 0.95$ to 0.98 ). Similarly, the proportion of current smokers with heavy consumption decreased from $42.3 \%$ in 2001 to $21.3 \%$ in 2016 (AOR $=0.93,95 \%$ CI 0.92 to 0.94 ). The proportion of smokers who had never attempted to quit decreased from $19.6 \%$ to $15.0 \%$, although this linear trend was not significant $(\mathrm{AOR}=0.98,95 \%$ CI 0.97 to 1.00$)$. We also observed significant reductions in the proportion of smokers who had made no quit attempt in the past 5 years $(36.2 \%$ to $25.8 \%$; $\mathrm{AOR}=0.97,95 \%$ CI 0.96 to 0.99$)$, who had made no quit attempt in the past 12 months (62.3\% to 54.4\%; $\mathrm{AOR}=0.98,95 \%$ CI 0.97 to 0.99$)$, who had no intention to quit in the next 6 months (45.6\% to 38.9\%; AOR $=0.97,95 \%$ CI 0.96 to 0.98$)$ and no intention to quit in the next 30 days $(83.9 \%$ to $72.1 \%$; AOR $=0.95,95 \%$ CI 0.93 to 0.96 ). The proportion who were happy to smoke for the rest of their lives also decreased from $18.9 \%$ in 2001 to $12.0 \%$ in 2016 (AOR $=0.97,95 \%$ CI 0.95 to 0.99; linear trend excludes 2007, 2008, 2009 and 2012, when the question was not asked).

The proportion of current smokers defined as a hardcore smoker decreased from $17.2 \%$ in 2001 to $9.1 \%$ in 2016 (AOR $=0.94$, $95 \%$ CI 0.92 to 0.96 ). The proportion of current smokers defined as having given up giving up was $1.1 \%$ in 2001 and $0.6 \%$ in 2016 (largest proportion observed was $1.4 \%$ in 2003; data not presented in figure 2 and significance testing not conducted due to 


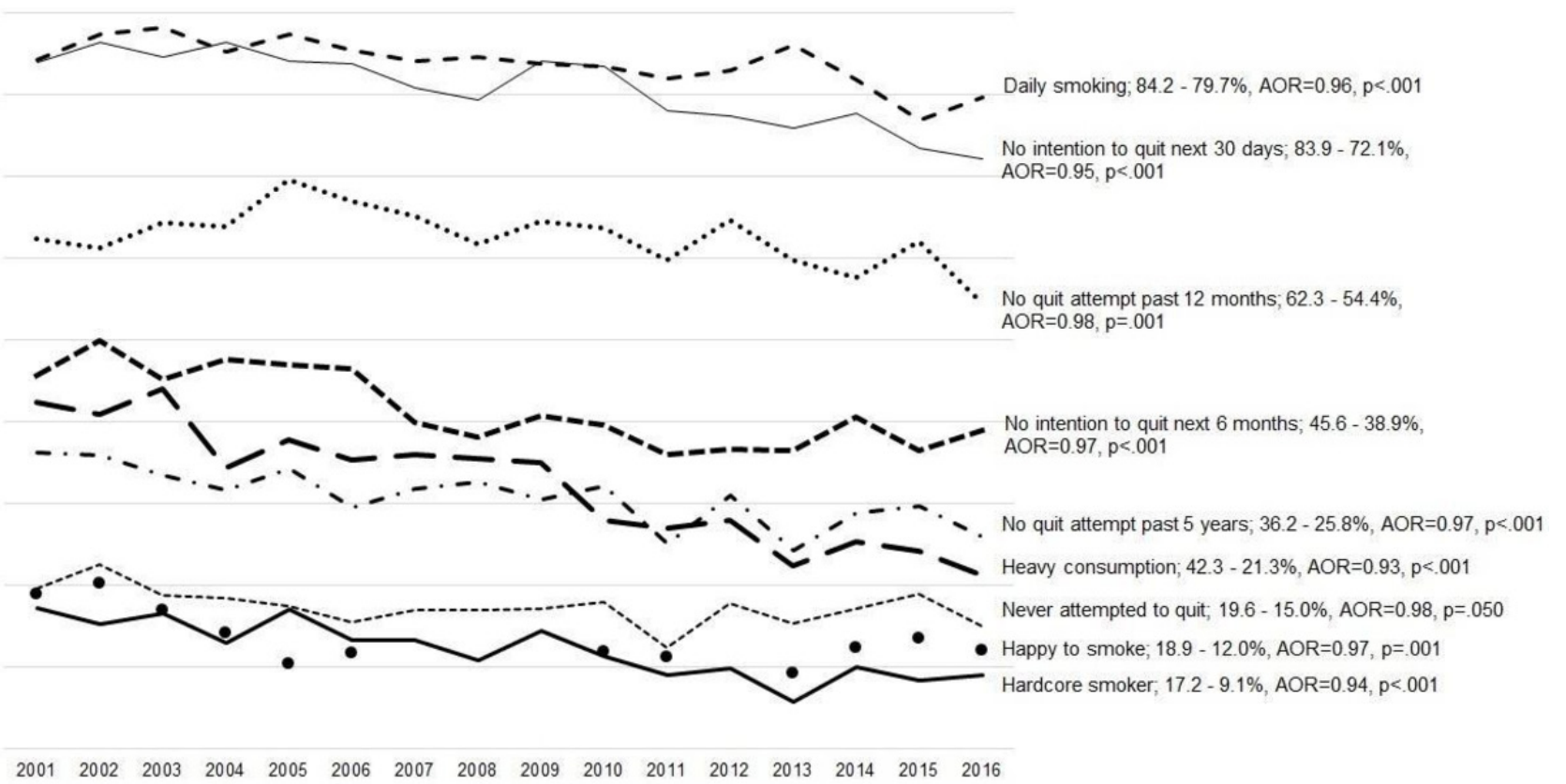

Figure 2 Prevalence of hardening indicators among current smokers aged 26+ in the state of Victoria, Australia, 2001 - 2016. Data points for every year, and Ns for every model, are presented in online appendix A in the supplementary material. AOR, OR adjusted for sex, age, education and socioeconomic status.

low probability outcome, but see online appendix A in the supplementary material for the proportion in each year).

\section{Subgroup analyses}

We tested a total of 36 interaction terms (yearxsex, yearxage, yearxeducation and yearxSES for nine outcomes, excluding given up giving $u p$ ), none of which were significant at the $p<0.01$ criterion level, and only three of which were significant at $p<0.05$. Specifically, there was some evidence of a yearxage interaction for the happy to smoke variable $(\mathrm{F}=5.10, \mathrm{p}=0.024$; online appendix $\mathrm{C}$ in the supplementary material). Stratified analyses indicated that the proportion of those aged $50+$ who were happy to smoke declined from $32.7 \%$ in 2001 to $18.7 \%$ in 2016 (AOR $=0.95$, $95 \%$ CI 0.93 to 0.97 ), while the proportion of people aged 26-49 years who were happy to smoke did not decline from a low of $12.4 \%$ in 2001 (to $9.1 \%$ in 2016 ; $\mathrm{AOR}=0.99,95 \%$ CI 0.96 to 1.02). There was also indication of a yearxeducation interaction for hardcore smokers $(\mathrm{F}=5.71, \mathrm{p}=0.017$; online appendix $\mathrm{D}$ in the supplementary material). Among those with low education, there was a slight linear decline over time in the proportion of hardcore smokers (AOR $=0.97,95 \%$ CI 0.94 to 0.99 ) even though proportions were similar in 2001 (18.4\%) and 2016 (18.1\%); the prevalence of hardcore smokers was lowest in 2011, 2012 and 2013 (11.8\%, 10.4\% and 10.6\%, respectively). By comparison, among those with higher education the prevalence of hardcore smokers decreased significantly between 2001 and 2016 (17.6\% to 5.6\%; $\mathrm{AOR}=0.92$, 95\% CI 0.90 to 0.94 ). Finally, there was a yearxSES interaction for no intention to quit in the next 6 months. Among low SES smokers, the proportion with no intention to quit in the next 6 months varied from year-to-year, showing a slight linear decline, even though proportions were similar in 2001 (44.4\%) and 2016 (45.0\%; AOR=0.98, 95\% CI 0.96 to 1.00). By comparison, the proportion of mid-high SES smokers with no intention to quit in the next 6 months decreased significantly (46.9\% to $35.3 \%$;
$\mathrm{AOR}=0.96,95 \% \mathrm{CI} 0.94$ to 0.97$)$. Results of all interaction tests and stratified models are provided in online appendices $\mathrm{B}-\mathrm{E}$ in the supplementary material.

\section{Sensitivity analyses}

We compared results using our definition of hardcore smokers and three alternatives (online appendix F in the supplementary material). Irrespective of definition, the prevalence of hardcore smokers declined significantly between 2001 and 2016. As expected, when the criterion of no quit attempt in the past 12 months was replaced with the criterion of never attempted to quit, fewer smokers were classified as hardcore $(17.2 \%$ cf. $5.3 \%$ in 2001 ; $9.1 \%$ cf. $2.0 \%$ in 2016). Also, when the criterion of heavy consumption was removed from the definition, the proportion of smokers classified as hardcore increased (eg, $17.2 \%$ cf. $31.1 \%$ in $2001 ; 9.1 \%$ cf. $26.7 \%$ in 2016).

\section{DISCUSSION}

Contrary to the hardening hypothesis, as smoking prevalence decreased in Victoria between 2001 and 2016, the prevalence of seven of eight hardening indicators also decreased. These results suggest that Victorian smokers may have softened over time. In addition, the proportion of current smokers classified as hardcore dropped below $10 \%$ in 2016, which equates to just $1.2 \%$ of the Victorian population aged $26+$ in 2016. The proportion of smokers categorised as having given up trying to quit was also consistently around 1\%. These results suggest that the comprehensive tobacco control programme implemented in Victoria has contributed to reductions in the prevalence of smoking and to reductions in how dependent and content the remaining smokers are to keep smoking.

Overall, there was minimal evidence of differences in hardening between demographic subgroups. There was some evidence of greater declines in particular indicators among smokers who 
were older, more highly educated and more socioeconomically advantaged. Stratified analyses identified some additional differences between subgroups in the extent to which particular hardening indicators changed (or did not change), however, there was no consistent pattern that would indicate hardening within any given subgroup. In particular, the results show that despite continued disparities in smoking rates, ${ }^{25}$ consumption decreased and quitting motivation and activity increased similarly across SES subgroups. Although Clare and colleagues found that the prevalence of hardcore smokers decreased only among high SES Australian smokers ${ }^{15}$ theirs was a household survey in all Australian states-some of which did not implement as comprehensive a tobacco control programme as Victoria-and was conducted prior to the large tax increases in Australia in 2010 and 2013, which are known to reduce socioeconomic disparities in smoking. ${ }^{39}$ The present findings suggest that the strategies implemented in Victoria have helped minimise hardening among even the most disadvantaged smokers.

It is important to note, however, that these changes may not translate into equivalent levels of quitting success; we were unable to measure change in how challenging smokers find it to maintain cessation. ${ }^{21}$ Distinguishing between changes in intentions and attempts to quit and in maintaining abstinence is important, because each requires different interventions. ${ }^{40}$ Clare et al concluded that the main drivers of hardcore smoking among disadvantaged smokers were greater dependence and lower quitting intentions, rather than fewer quit attempts. ${ }^{15}$ Another Australian study similarly found that although disadvantaged smokers were equally likely to attempt to quit, they experienced less success, leading to disparities in quit proportions. ${ }^{41}$ Past research in Victoria, however, found that although the rate of successful quitting was lower among smokers in low SES than mid-high SES areas in both 2004-2005 and 2015, it had increased for both groups and the gap remained stable. ${ }^{25}$ The present findings showing little difference in quit intentions, attempts or markers of dependence over time suggest that disadvantaged smokers in Victoria are equally interested in quitting; however, future work is required to determine how best to ensure quit attempts translate to successful cessation.

By examining a range of indicators within the same population and over the same time period, this study overcomes limitations associated with the inconsistency in measures used across past studies. ${ }^{21}$ We found similar patterns regardless of hardening indicator, and our finding of declining prevalence of hardcore smokers was robust to various definitions. Nonetheless, some hardening indicators examined in previous studies were not available for analysis (eg, time-to-first-cigarette, ${ }^{21}$ comorbidities such as mental health problems ${ }^{14}$ ). Recruitment by telephone would have also excluded individuals who are homeless or being treated in psychiatric institutions, who are more likely to smoke. ${ }^{6}$ This survey also did not contain sufficient numbers of Aboriginal peoples and Torres Strait Islanders-who experience substantially higher smoking rates and are the most disadvantaged social group in Australia ${ }^{42} 43$ - to permit meaningful subgroup analyses. While these findings are largely consistent with previous studies showing no evidence of hardening in Australia ${ }^{14} 15$ and internationally, ${ }^{3} 468-11$ most of this evidence comes from high income countries with comprehensive tobacco control programmes and relatively low smoking prevalence.

Smoking frequency and the average number of cigarettes per day were used to indicate dependence; however, consumption can also reflect the strength of polices such as tobacco taxes and smokefree laws, ${ }^{38}$ and some psychological aspects of nicotine dependence can persist even among smokers who reduce their consumption. ${ }^{6}$ Smokers can also compensate for smoking fewer cigarettes by taking more and deeper puffs from each cigarette, thereby maintaining their nicotine intake. ${ }^{644}$ There is also evidence that tobacco manufacturers have made design modifications that potentially allow smokers to extract more nicotine from each cigarette. ${ }^{45}$ Together, these findings raise the possibility that our consumption measures may not reliably reflect dependence.

The major strength of this study is the extended period over which hardening indicators were examined, which is important for reliably assessing changes over time, especially within subgroups. Other strengths include the large sample size, the consistent approach to data collection over time (apart from changes to recruitment methodology to reflect changing patterns of landline and mobile phone usage ${ }^{25}$ ) and the use of a random sample representative of the Victorian population.

\section{CONCLUSION}

The underlying logic of the hardening hypothesis is that the remaining population of smokers will comprise individuals who find quitting more difficult, if those who have already quit are presumed to find quitting easier than those who have not yet been successful. Our findings do not necessarily challenge this logic. But what they do suggest is that the mass media campaigns, graphic health warnings, plain packaging, substantial tobacco taxes and smokefree restrictions (among other interventions; figure 1) implemented in Victoria have successfully reduced consumption and promoted interest in quitting among even those smokers who have not yet succeeded in quitting. ${ }^{21}$ Rather than supporting the modification or even abandonment of the current strategy, our findings show the importance of sustaining and strengthening Victoria's comprehensive, evidence-based tobacco control policies. Such interventions could be implemented alongside enhanced efforts targeting and supporting disadvantaged groups who, despite showing no evidence of hardening, nonetheless experience a disproportionate burden from tobacco use.

\section{What this paper adds}

- Evidence from the USA, Europe, New Zealand and Australia tends not to support the hardening hypothesis, observing decreases rather than increases in the proportion of hardcore smokers as smoking prevalence declines.

- However, some studies suggest that while the overall proportion of hardcore smokers is not increasing, the remaining smoking population may be increasingly composed of subgroups who experience greater difficulty in quitting.

- The current study tested the hardening hypothesis among smokers in the Australian state of Victoria, and extended previous work by examining changes in multiple hardening indicators over an extended 16 -year period, among demographic subgroups as well as the overall population.

- Contrary to the hardening hypothesis, as the prevalence of smoking in Victoria declined so did the prevalence of hardcore smokers and eight of nine hardening indicators. On the whole, these trends did not differ by sex, age, education or socioeconomic status.

- The comprehensive tobacco control programme implemented in Victoria since 2001 appears to have been successful in reducing smoking prevalence as well as dampening the desire to keep smoking among the remaining population of smokers.

Contributors EB, SJD and MAW conceived the study. LH and SJD managed data collection, management and preparation. EB analysed the data. EB and EMG drafted the manuscript with contributions from all authors. All authors approved the final manuscript. 
Funding The Victorian Smoking and Health survey was auspiced by Quit Victoria, with funding from VicHealth, the State Government of Victoria and Cancer Council Victoria. The funders had no influence on the decision to submit the paper for publication.

\section{Competing interests None declared.}

Patient consent for publication Not required.

Ethics approval The survey was approved by the Cancer Council Victoria Human Ethics Committee (HREC 0018).

Provenance and peer review Not commissioned; internally peer reviewed.

Data sharing statement No data are available.

\section{ORCID iDs}

Emily Brennan http://orcid.org/0000-0001-9779-0210

Elizabeth M Greenhalgh http://orcid.org/0000-0002-7054-0382

Sarah J Durkin 0000-0002-2795-6454

Michelle M Scollo http://orcid.org/0000-0002-6583-4730

Linda Hayes 0000-0001-6456-8920

Melanie A Wakefield 0000-0002-6183-5699

\section{REFERENCES}

1 World Health Organization. WHO report on the global tobacco epidemic, 2017: monitoring tobacco use and prevention policies. Geneva: World Health Organization, 2017. Available: http://www.who.int/tobacco/global_report/2017/en/ [Accessed Sept 2018].

2 Warner KE, Burns DM. Hardening and the hard-core smoker: concepts, evidence, and implications. Nicotine Tob Res 2003:5:37-48.

3 Edwards R, Tu D, Newcombe R, et al. Achieving the tobacco endgame: evidence on the hardening hypothesis from repeated cross-sectional studies in New Zealand 2008-2014. Tob Control 2017;26:399-405.

4 Fernández E, Lugo A, Clancy L, et al. Smoking dependence in 18 European countries: hard to maintain the hardening hypothesis. Prev Med 2015;81:314-9.

5 Polosa R, Rodu B, Caponnetto P, et al. A fresh look at tobacco harm reduction: the case for the electronic cigarette. Harm Reduct J 2013;10.

6 Smith PH, Rose IS, Mazure CM, et al. What is the evidence for hardening in the cigarette smoking population? Trends in nicotine dependence in the U.S., 2002-2012. Drug Alcohol Depend 2014;142:333-40.

7 Bommelé J, Nagelhout GE, Kleinjan M, et al. Prevalence of hardcore smoking in the Netherlands between 2001 and 2012: a test of the hardening hypothesis. BMC Public Health 2016:16:754.

8 Kulik MC, Glantz SA. The smoking population in the USA and EU is softening not hardening. Tob Control 2016;25:470-5.

9 Kulik MC, Glantz SA. Softening among U.S. smokers with psychological distress: more quit attempts and lower consumption as smoking drops. Am J Prev Med 2017:53:810-7.

10 Giovino GA, Chaloupka FJ, Hartman AM, et al. Cigarette smoking prevalence and policies in the 50 states: an era of change - the Robert Wood Johnson Foundation ImpacTeen tobacco chart book. Buffalo, NY: University at Buffalo, State University of New York, 2009. Available: https://tobacconomics.org/wp-content/uploads/2014/02/ chartbook_final060409.pdf

11 Cohen JE, McDonald PW, Selby P. Softening up on the hardening hypothesis. Tob Control 2012:21:265-6.

12 Ferketich AK, Gallus S, Colombo P, et al. Hardcore smoking among Italian men and women. Eur J Cancer Prev 2009:18:100-5.

13 Lund M, Lund KE, Kvaavik E. Hardcore smokers in Norway 1996-2009. Nicotine Tob Res 2011:13:1132-9.

14 Mathews R, Hall WD, Gartner CE. Is there evidence of 'hardening' among Australian smokers between 1997 and 2007? Analyses of the Australian National Surveys of Mental Health and Well-Being. Aust N Z J Psychiatry 2010;44:1132-6.

15 Clare P, Bradford D, Courtney RJ, et al. The relationship between socioeconomic status and 'hardcore' smoking over time--greater accumulation of hardened smokers in lowSES than high-SES smokers. Tob Control 2014;23:e133-8.

16 Irvin JE, Hendricks PS, Brandon TH. The increasing recalcitrance of smokers in clinical trials II: pharmacotherapy trials. Nicotine Tob Res 2003:5:27-35.

17 Irvin JE, Brandon TH. The increasing recalcitrance of smokers in clinical trials. Nicotine Tob Res 2000;2:79-84.

18 Docherty G, McNeill A, Gartner C, et al. Did hardening occur among smokers in England from 2000 to 2010? Addiction 2014;109:147-54.

19 Fagerström K, Furberg H. A comparison of the Fagerström test for nicotine dependence and smoking prevalence across countries. Addiction 2008;103:841-5.

20 Winter KM. Hardcore smoking does not necessarily indicate hardening. Addiction 2014; 109:681.

21 Hughes JR. The hardening hypothesis: is the ability to quit decreasing due to increasing nicotine dependence? A review and commentary. Drug Alcohol Depend 2011:117:111-7.
22 Etter J-F. Hardening the methods, a comment on Fagerstrom \& Furberg 2008. Addiction 2008:103:1576-76.

23 Germain D, Durkin S, Scollo M, et al. The long-term decline of adult tobacco use in Victoria: changes in smoking initiation and quitting over a quarter of a century of tobacco control. Aust N Z J Public Health 2012;36:17-23.

24 Wakefield MA, Coomber K, Durkin SJ, et al. Time series analysis of the impact of tobacco control policies on smoking prevalence among Australian adults, 2001-2011. Bull World Health Organ 2014;92:413-22.

25 Hayes L, Durkin S, Bain E. Smoking prevalence and consumption in Victoria: key findings from the Victorian Smoking and Health population surveys. Melbourne Australia: Centre for Behavioural Research in Cancer, Cancer Council Victoria, 2016. Available: http://www.cancervic.org.au/downloads/cbrc_research_papers/R16_LH_ Smoking_prev_and_consumption_in_VIC.pdf

26 Australian Institute of Health and Welfare. National Drug Strategy Household Survey (NDSHS) 2016 key findings data tables. Canberra, Australia: Australian Institute of Health and Welfare, 2017. Available: https://www.aihw.gov.au/reports/illicit-use-ofdrugs/2016-ndshs-detailed/data [Accessed Sept 2018].

27 Wakefield MA, Hayes L, Durkin S, et al. Introduction effects of the Australian plain packaging policy on adult smokers: a cross-sectional study. BMJ Open 2013;3:e003175

28 Hayes L, Wakefield MA, Bain E. Change in public support for the introduction of plain packaging and new, enlarged graphic health warnings in the Australian state of Victoria, 2011-2013. Tob Control 2017:26:627-8.

29 Augustson E, Marcus S. Use of the Current Population Survey to characterize subpopulations of continued smokers: a national perspective on the "hardcore smoker phenomenon. Nicotine Tob Res 2004;6:621-9.

30 Sorg A, Xu J, Doppalapudi SB, et al. Hardcore smokers in a challenging tobacco control environment: the case of Missouri. Tob Control 2011;20:388-90.

31 Goodwin RD, Wall MM, Gbedemah M, et al. Trends in cigarette consumption and time to first cigarette on awakening from 2002 to 2015 in the USA: new insights into the ongoing tobacco epidemic. Tob Control 2018;27:379-84.

32 Emery S, Gilpin EA, Ake C, et al. Characterizing and identifying "hard-core" smokers: implications for further reducing smoking prevalence. Am J Public Health 2000:90:387-94.

33 Walsh RA, Paul CL, Tzelepis F, et al. Quit smoking behaviours and intentions and hardcore smoking in New South Wales. Health Promot J Aust 2006;17:54-60.

34 Australian Bureau of Statistics. Technical paper: Socio-Economic Indexes for Areas (SEIFA) 2011. Canberra, Australia: Australian Bureau of Statistics, 2013. Available: http://www.ausstats.abs.gov.au/ausstats/subscriber.nsf/0/22CEDA8038AF7A0DCA25 7B3B00116E34/\$File/2033.0.55.001\%20seifa\%202011\%20technical\%20paper.pdf [Accessed Sep 2018].

35 Australian Bureau of Statistics. Population by age and sex, Australian states and territories - 2006 Census Edition. Canberra, Australia: Australian Bureau of Statistics, 2008.

36 Australian Bureau of Statistics. Population by age and sex, Australian states and territories - 2011 Census Edition. Canberra, Australia: Australian Bureau of Statistics, 2013.

37 Costa ML, Cohen JE, Chaiton MO, et al. "Hardcore" definitions and their application to a population-based sample of smokers. Nicotine Tob Res 2010;12:860-4.

38 Warner KE. Tobacco control policy. San Francisco, CA: Jossey-Bass, 2006.

39 Hill S, Amos A, Clifford D, et al. Impact of tobacco control interventions on socioeconomic inequalities in smoking: review of the evidence. Tob Control 2014:23:e89-97.

40 Hughes JR, Brandon TH. A softer view of hardening. Nicotine Tob Res 2003;5:961-2.

41 Greenhalgh E, Bayly M, Brennan E, et al. The great socioeconomic smoking divide: is the gap widening in Australia, and why? Tob Prev Cessat 2018;4(Supplement):A116.

42 van der Sterren A, Greenhalgh EM, Knoche D, et al. Aboriginal peoples and Torres Strait Islanders: social disadvantage, health and smoking —an overview. In: Scollo MM, Winstanley MH, eds. Tobacco in Australia: facts and issues. Melbourne, Australia: Cancer Council Victoria, 2016. Available: http://www.tobaccoinaustralia.org.au/ chapter-8-aptsi/8-1-overview

43 van der Sterren A, Greenhalgh EM, Knoche D, et al. Prevalence of tobacco use among Aboriginal peoples and Torres Strait Islanders. In: Scollo MM, Winstanley MH, eds. Tobacco in Australia: facts and issues. Melbourne, Australia: Cancer Council Victoria, 2016. Available: http://www.tobaccoinaustralia.org.au/chapter-8-aptsi/8-3prevalence-of-tobacco-use-among-aboriginal-peo

44 Jarvis MJ, Giovino GA, O'Connor RJ, et al. Variation in nicotine intake among U.S. cigarette smokers during the past 25 years: evidence from NHANES surveys. Nic Tob Res 2014;16:1620-8.

45 Connolly GN, Alpert HR, Wayne GF, et al. Trends in nicotine yield in smoke and its relationship with design characteristics among popular US cigarette brands, 19972005. Tob Control 2007:16:e5.

46 Greenhalgh EM, Bayly M, Winstanley MH. Smoking by Australian states and territories In: Scollo MM, Winstanley MH, eds. Tobacco in Australia: facts and issues. Melbourne, Australia: Cancer Council Victoria, 2017. Available: http://www.tobaccoinaustralia. org.au/chapter-1-prevalence/1-13-smoking-states-territories 